\title{
Starch films for agronomic applications: comparative study of urea and glycerol as plasticizers
}

\author{
Florencia Versino ${ }^{1,2}$, María Alejandra García ${ }^{1,3}$ \\ ${ }^{1}$ Centro de Investigación y Desarrollo en Criotecnología de Alimentos, CIDCA (UNLP-CONICET-CICPBA), Facultad de \\ Ciencias Exactas, UNLP, 47 y 116, (CP.1900) La Plata, Argentina. \\ ${ }^{2}$ Departamento de Ingeniería Química, Facultad de Ingeniería, Universidad Nacional de La Plata (UNLP), 47 y 115 , \\ (CP.1900) La Plata, Argentina. \\ E-mail: florencia.versino@ing.unlp.edu.ar \\ ${ }^{3}$ Departamento de Química, Facultad de Ciencias Exactas, Universidad Nacional de La Plata (UNLP), 47 y 115, (CP.1900) \\ La Plata, Argentina. \\ E-mail: magarcia@quimica.unlp.edu.ar
}

\begin{abstract}
This work aims to study the effects of urea, glycerol and their mixture as plasticizers for cassava starch films, regarding their impact on the material structure, water susceptibility, barrier and mechanical properties. All plasticizers were compatible with starchbased matrices, without detecting migration at the plasticizers level tested. In general water related properties were not affected. Plasticizer-polymer interactions as well as those involving water molecules were evidenced by ATR-FTIR spectra. Urea resulted the most efficient plasticizer, since it lowers glass transition temperature values and enhances mechanical properties. The co-plasticization of the starch films with glycerol and urea mixture resulted in poorer mechanical performance, though with higher light absorption which is relevant considering the potential film applications as mulching functionalized cover material.
\end{abstract}

Keywords-cassava starch, barrier properties, plasticizer interaction, mechanical properties, urea.

\section{INTRODUCTION}

Research related to functionalised biodegradable materials with active compounds is highly demanded for biomedical and pharmaceutical uses. However, the applications reported in the agronomic area are scarce, being these mainly focused on fertilisers' encapsulation $[1,2]$. Likewise, the great plastics consumption for agronomic purposes has triggered the development of biodegradable materials [3-5]. In this regard, the inclusion of fertilisers to biodegradable films could help diminishing pollution as well as increasing crop efficiency and decreasing agrochemical use; thus, providing a greener alternative. The addition of urea, a common fertiliser, could not only functionalise but also plasticise the film matrix being this later released to the soil.

In general, plasticizers are included in material formulations for two main purposes: as processing aid agents and as final product properties modifiers [6]. In the first case, plasticizers lower the processing temperature, reduce sticking in moulds and enhance wetting. In the second one, they increase the temperature range of usage; increase flexibility and toughness; and lower the glass transition temperature. There is a consensus in the scientific community that plasticizers reduce intermolecular forces along the polymer chains, thus increasing the free volume and chain movements However, the plasticizer selection depends on its compatibility, efficiency and permanence in the polymer matrix [6]. Moreover, plasticisation is particularly important on biopolymer films, since the dehydration of these structures produces strong cohesive films with poor mechanical and barrier properties [7]. Since most plasticizers contain hydrophilic groups, these compounds can interact by means of hydrogen bonds not only with polymer matrix but also with water molecules, increasing therefore films moisture absorption [8]. As regards starchbased materials, many studies have been carried out on different plasticizers to evaluate their performance, being polyols -especially glycerol- the most commonly used [923].

In comparison to polyols, urea exhibits a strong hydrophilicity due to its chemical structure -containing two amino groups and one carbonyl group- and a tendency to crystallise. It has been used for plasticisation of starch [17, 24-26], as well as cellulose [27], poly(vinyl alcohol) [28] and soy protein [29]. 
In respect of external plasticization, hydrocolloid-based films admit a maximum amount of plasticizer that is limited by their migration towards the film surface. As regards glycerol plasticised-films migration is evidenced by the oily appearance of films surface [30,31], whereas when urea is used superficial crystallisation can occur [26]. Therefore, several studies on plasticizer content effect have been reported, being $30 \% \mathrm{w} / \mathrm{w}$ of dry basis the maximum concentrations reported for both glycerol and urea in starch-based materials $[20,26,30,32]$. In addition, references on plasticizers-mixtures to extend migrations limits can been found, for instance urea/formaldehyde and urea/ethanolamine [24, 25]. The use of glycerol-urea, in particular, blends has been reported in thermoplastic starch (TPS) films [2, 33] Nonetheless, no research addressing urea and glycerol mixture effect on cassava starch films obtained by casting has been published hitherto.

In this paper, we are therefore attempting to reveal the structure and behaviour of urea, glycerol and their mixture as plasticizers for cassava starch films, regarding the effects on the water susceptibility, barrier and mechanical properties of the films considering potential agronomic applications.

\section{MATERIALS AND METHODS \\ 2.1 Materials}

Native cassava (Manihot esculenta) starch was purchased from Cooperativa de Productores de Jardín América Ltda. (Misiones, Argentina). Reagent grade glycerol (CAS\# 5681-5, Anedra, Argentina) and urea (CAS\# 57-13-6, Biopack, Argentina) were used as plasticizers.

\subsection{Film preparation}

Native cassava starch films were prepared by casting and plasticised with glycerol, urea or its half-and-half mixture (w/w). Aqueous suspensions of $3 \% \mathrm{w} / \mathrm{w}$ starch were gelatinised at $90{ }^{\circ} \mathrm{C}$ during $20 \mathrm{~min}$. Plasticizers were added after gelatinisation in a ratio of 25:100 of plasticizers to starch (w/w). A control film without any plasticizer (C) was also prepared as matrix reference.

Approximately $20 \mathrm{~g}$ of the film-forming suspensions were cast onto Petri dishes (diameter $8.7 \mathrm{~cm}$ ) and later dried in a ventilated oven (GMX 9203A PEET LAB, USA) at $50{ }^{\circ} \mathrm{C}$ for $4 \mathrm{~h}$; films were removed from the plates and stored at $20^{\circ} \mathrm{C}$ and $65 \%$ relative humidity $(\mathrm{RH})$ for at least $48 \mathrm{~h}$.
2.3 Film properties
2.3.1 Wettability and water content
2.3.1.1 Water content

Films moisture content was determined gravimetrically by measuring the weight loss of films upon drying in an oven at $105{ }^{\circ} \mathrm{C}$ until constant weight. Reported values correspond to the mean value of three determinations.

\subsubsection{Water sorption}

Water sorption was measured gravimetrically on $2 \mathrm{~cm} \times 2$ $\mathrm{cm}$ films exposed to $100 \%$ constant relative humidity at $20{ }^{\circ} \mathrm{C}$. Films were previously dried to constant weight in an anhydrous $\mathrm{CaCl}_{2}$ atmosphere with an accuracy of \pm $0.0001 \mathrm{~g}$. Water uptake curves were fitted to the experimental model of Elizaldey col. [34]:

$$
q=(Q t) /(B+t)
$$

Where $\mathrm{q}$ and $\mathrm{Q}$ are water taken up at time $(\mathrm{t})$ and at equilibrium respectively and $\mathrm{B}$ is the time needed for samples to gain half of equilibrium value. Water content are given on dry basis; therefore, the samples dry matter was determined gravimetrically by oven drying at $105^{\circ} \mathrm{C}$. At least three replicates were measured for each sample. By differentiation of Eq. (1) a specific rate of water uptake constant $(\mathrm{K})$ was determined as follows:

$$
\begin{aligned}
& K=1 /(Q B) \\
& 2.3 .1 .3 \quad \text { Wettability }
\end{aligned}
$$

Films wetting was evaluated through static contact angle measurements by the sessile drop method, using a RaméHart Model 250 Standard Goniometer (USA). A 2 - $3 \mu \mathrm{L}$ doubly distilled and deionized water droplet was released on the film surface, then the contact angle was calculated from a digital picture taken as soon as the droplet had reached the sample to avoid the anomalous behaviour of swelling. The contact angle $(\theta)$ was determined from the angle made between the baseline representing the film surface (liquid-solid interface) and the tangent to the droplet surface curvature (liquid-air interface). The mean value of ten replicates were taken on each film sample.

\subsubsection{Optical and barrier properties \\ 2.3.2.1 Water vapour permeability (WVP)}

Water vapour permeability (WVP) tests were conducted using ASTM Standard Method E96 with several modifications according to [30]. After steady-state condition was reached, the acrylic permeation cells were weighed $(0.0001 \mathrm{~g})$ at initial time and at $1 \mathrm{~h}$ interval over 8hs. The WVP (g/m s Pa) was calculated considering the thickness of each tested film, as well as the cell area and the water vapour partial pressure difference across the film at $20^{\circ} \mathrm{C}$. Samples were analysed at least in triplicate. Additionally, a digital coating thickness gauge for nonconductive materials CM-8822 (SolTec, Argentina), was used to evaluate the films thickness. Ten measurements were randomly taken at different locations for each specimen and the mean value was reported.

\subsubsection{Optical properties}

To evaluate the films light barrier capacity the absorbance spectrum $(200-700 \mathrm{~nm})$ was recorded using a HITACHI U-1900 Spectrophotometer (Japan). Films were cut into rectangles $(3 \mathrm{~cm} \times 1 \mathrm{~cm})$ and placed on the internal side of a quartz spectrophotometer cell. Film opacity and UVbarrier capacity (AU $\times n$ m) were defined as the area under the recorded curve between $400-700 \mathrm{~nm}$ and $200-400$ 
$\mathrm{nm}$, respectively, as described by Castilloy col. [35] and the standard test method for haze and luminous transmittance of transparent plastics recommendations ASTMD1003-00 Standard.

\subsubsection{Film microstructure and mechanical properties}

\subsubsection{Fourier Transform Infrared Spectroscopy (FTIR)}

The IR spectra of plasticised films were measured in a FTIR Nicolet-iS10 Thermo Scientific Spectrometer (USA) with Attenuated Total Reflection (ATR) accessory. Spectra were taken in the wavenumber range: $4000-500 \mathrm{~cm}^{-1}$ by accumulation of 64 scans at $4 \mathrm{~cm}^{-1}$ resolution. Data was analysed by using the Software Omnic 9 (Thermo Scientific, USA). The spectral deconvolution of the data was performed using curve fitting algorithms within the following regions: $3700-$ $2800 \mathrm{~cm}^{-1}, 1700-1500 \mathrm{~cm}^{-1}$ and $1200-900 \mathrm{~cm}^{-1}$, as described in a previous work [8].

\subsubsection{Differential Scanning Calorimetry} (DSC)

Thermal properties of plasticised films were analysed by DSC employing a Q100 TA Instruments DSC equipment (USA) controlled by a TA 5000 module, with a quench cooling accessory, under a $\mathrm{N}_{2}$ atmosphere $(20 \mathrm{ml} / \mathrm{min})$. Film samples (5 - $6 \mathrm{mg}$ ) were weighed in aluminium pans and hermetically sealed, using an empty pan as a reference. Samples were analysed between -80 and 12 ${ }^{\circ} \mathrm{C}$, at a $10{ }^{\circ} \mathrm{C} / \mathrm{min}$ heating rate. Glass transition temperature $\left(\mathrm{Tg},{ }^{\circ} \mathrm{C}\right)$ was determined using the Universal Analysis V1.7 F software (TA Instruments, USA). All measurements were performed at least by duplicate.

\subsubsection{Mechanical testing}

Mechanical performance of the studied films was evaluated by tensile tests using a texturometerTA.XT2iStable Micro Systems (UK) with a tension grip system A/TG. Ten probes of $7 \mathrm{~mm} \times 60 \mathrm{~mm}$ were assayed for each sample and stress-strain curves were recorded. Maximum tensile strength $\left(\mathrm{R}_{\max }\right)$, elongation at break $\left(\mathrm{E}_{\max }\right)$, elastic modulus $(\mathrm{Ec})$ and tenacity $(\mathrm{Eg})$ were calculated according to the ASTM D882 - 00 Standard. At least ten replicates were measured, and the mean value was reported. Additionally, films thickness was determined as described previously.

\subsubsection{Scanning Electron Microscopy (SEM)}

Besides, some tested probes were mounted on bronze stubs and coated with a gold layer $(40-50 \mathrm{~nm})$ to be studied by SEM with a FEI QUANTA 200 SEM (Japan) with Apollo 40 electron detector. All samples were analysed using an accelerating voltage of $10 \mathrm{kV}$, under high vacuum mode.

\subsubsection{Statistical analysis}

Multifactor analyses of variance were performed using InfoStat Software [36]. Differences in the properties of the films were determined by Fisher's Least Significant Difference (LSD) mean discrimination test, using a significance level of $\alpha=0.05$. In addition, in order to analyse the interdependence and variability of the results obtained a Principal Components Analysis (PCA) was carried out. The software (InfoStat) was used for the analysis considering two main components. From the analysis performed, the Biplot graph and the cophenetic correlation coefficient were reported, the latter being indicative of the efficiency of the variable clustering.

\section{RESULTS AND DISCUSSION}

I.1. Wettability and water content

Since both plasticizers evaluated present a hydrophilic nature, films water susceptibility was studied by different simple tests: water sorption, moisture content and contact angle.

Films water uptake behaviour was similar for all plasticised films. A relatively good fit $\left(\mathrm{r}^{2}>0.920\right)$ of the experimental data to the model of Elizaldey col. [34] was observed (Fig.1), from which parameters Q, B and K were obtained (Table 1).
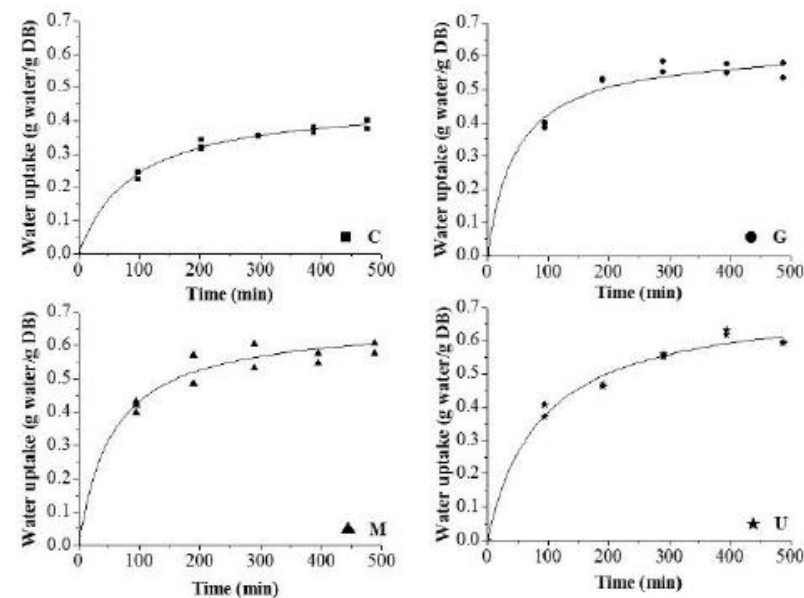

Fig. 1: Predicted (solid lines) and experimental (single points) sorption curves at $100 \%$ RH of cassava starch-

based films: unplasticized $(C)$ and plasticised with glycerol $(G)$, urea $(U)$ and the mixture of both $(M) .(D B=$ dry basis)

Films containing glycerol (G, M) reached similar equilibrium water uptake $(\mathrm{Q})$ and time needed to gain half of equilibrium value (B), while films plasticised only with urea $(U)$ presented significantly higher values $(\mathrm{p}<0.05)$ in both parameters though showing lower water uptake rate (K). Control films (C), on the other hand, gave intermediate $\mathrm{K}$ values compared to those of plasticised films however showing significantly lower $Q$ values 
Table 1. Water uptake kinetic parameters, water content and wettability of control cassava starch films $(C)$ and films plasticized with: glycerol $(G)$, urea $(U)$ and their mixture $(M)$.

\begin{tabular}{|c|c|c|c|c|c|}
\hline \multirow[b]{2}{*}{ Film } & \multicolumn{3}{|c|}{ Water uptake } & \multirow{2}{*}{$\begin{array}{c}\text { Water content } \\
(\%)\end{array}$} & \multirow{2}{*}{$\begin{array}{c}\text { Contact angle } \\
(\Theta)\end{array}$} \\
\hline & $\begin{array}{c}\mathrm{Q} \\
\text { (g water/g DB*) }\end{array}$ & $\begin{array}{c}\text { B } \\
(\mathrm{hr})\end{array}$ & $\begin{array}{c}\mathrm{K} \\
(\mathrm{g} \mathrm{DB} / \mathrm{g} \text { water } \mathrm{hr})\end{array}$ & & \\
\hline $\mathrm{C}$ & $0.45 \pm 0.02^{a}$ & $1.5 \pm 0.02 b$ & $1.5 \pm 0.07 \mathrm{ab}$ & $13.4 \pm 0.8^{a}$ & $38.2 \pm 4.3^{\mathrm{a}}$ \\
\hline G & $0.64 \pm 0.01 b$ & $0.8 \pm 0.01^{a}$ & $2.0 \pm 0.01 \mathrm{~b}$ & $21.1 \pm 0.4^{\mathrm{d}}$ & $48.9 \pm 2.9^{b}$ \\
\hline M & $0.67 \pm 0.01 \mathrm{bc}$ & $0.9 \pm 0.05^{a}$ & $1.7 \pm 0.10^{b}$ & $17.7 \pm 0.9^{\mathrm{c}}$ & $46.6 \pm 3.6^{b}$ \\
\hline $\mathrm{U}$ & $0.71 \pm 0.02^{\mathrm{c}}$ & $1.4 \pm 0.11^{b}$ & $1.05 \pm 0.10^{\mathrm{a}}$ & $15.8 \pm 0.9^{b}$ & $46.5 \pm 3.3^{b}$ \\
\hline
\end{tabular}

Reported values correspond to the mean \pm standard deviation.

$* \mathrm{DB}=$ dry basis

$(\mathrm{p}<0.05)$. As outlined by Elizaldey col. [34] at RH > 90, water uptake represent mostly multilayer water, water held

in voids, crevices and capillaries. In the absence of plasticizer films present a more compact structure [6], therefore holding less water at the same equilibrium moisture than plasticised films.

The water content of the plasticised polymer samples ranged between 15.8 and $21.1 \%$, with significant differences $(p<0.05)$ among the three samples tested, and significantly higher than unplasticized films (C) water content (Table 1).Even though all samples contained the same amount of plasticizer $(25 \% \mathrm{w} / \mathrm{w})$, the addition of urea resulted in lower moisture content, indicating differential interaction among polymer-plasticizer-water depending on the plasticizer type.

The contact angle measurement is a useful tool to determine the hydrophobic or hydrophilic character of a film surface: low contact angle values $\left(\Theta<90^{\circ}\right)$ correspond to surfaces that are more wettable, on the contrary, hydrophobic surfaces show high values $\left(\Theta>90^{\circ}\right)$ of this parameter [37]. All films presented low contact angle values (Table 1). Nevertheless, a slight but significant $(\mathrm{p}<0.05)$ increase with respect to unplasticized films (C) was observed with plasticizers inclusion independently of their nature or concentration $(G, M$ and U). Correspondingly, reported values of corn starch based films confirm the hydrophilic nature of these materials, though the comparison of contact angle values results difficult, since it strongly depends on additives and film [38, 39].

\section{I.2. Barrier properties}

Even though $G$ films plasticised presented higher mean WVP values than those plasticised with $\mathrm{M}$ and $\mathrm{U}$ there were no significant differences $(p>0.05)$ among plasticised films (Table 2), yet these resulted significantly $(\mathrm{p}<0.05)$ lower than $\mathrm{C}$ films WVP. These results are in accordance with other published works, considering that all samples contained the same total amount of plasticizer. Plasticizers interfere with polymeric chain association decreasing the rigidity of the network, producing a less ordered film structure, such an effect has great impact on films WVP [6]. In comparison to unplasticized cassava starch films, WVP decreases significantly $(\mathrm{p}<0.05)$ with $25 \%$ of plasticizer addition, since more homogeneous and compact films are obtained without pores or cracks evidenced by SEM [30, 32].

Table 2. Light barrier capacity and WVP of control cassava starch films $(C)$ and films plasticized with: glycerol $(G)$, urea $(U)$ and their mixture $(M)$.

\begin{tabular}{|c|c|c|c|}
\hline Film & $\begin{array}{l}\text { WVP } \\
\left(\mathrm{g} / \mathrm{m} \mathrm{s} \mathrm{Pa} \times 10^{10}\right)\end{array}$ & $\begin{array}{l}\text { Opacity } \\
(\mathrm{AU} \times \mathrm{nm})\end{array}$ & $\begin{array}{l}\text { UV-barrier } \\
(\mathrm{AU} \times \mathrm{nm})\end{array}$ \\
\hline $\mathrm{C}$ & $1.53 \pm 0.3^{b}$ & $32.69 \pm 2.1^{\mathrm{c}}$ & $40.84 \pm 1.3^{\mathrm{a}}$ \\
\hline $\mathrm{G}$ & $1.03 \pm 0.1^{\mathrm{a}}$ & $28.83 \pm 2.9 \mathrm{bc}$ & $39.43 \pm 3.1^{\mathrm{a}}$ \\
\hline M & $0.99 \pm 0.1^{a}$ & $25.03 \pm 3.0^{a b}$ & $46.00 \pm 3.2 b$ \\
\hline $\mathrm{U}$ & $0.93 \pm 0.1^{a}$ & $23.45 \pm 2.5^{\mathrm{a}}$ & $46.90 \pm 0.94 b$ \\
\hline
\end{tabular}

Reported values correspond to the mean \pm standard deviation.

With regard to films light barrier capacity, the UV barrier capacity $(200-400 \mathrm{~nm})$ was higher for films plasticised with urea, due to its characteristic absorption peak. On the contrary, unplasticized films showed higher absorption in the visible region $(400-700 \mathrm{~nm})$ attributed to a more compact structure, hence the addition of plasticizer significantly reduced $(\mathrm{p}<0.05)$ films opacity being glycerol influence lower than that of urea.

I.3. Film microstructure and mechanical properties

I.3.1. Fourier Transform Infrared Spectroscopy (FTIR)

FTIR spectra for pure components: starch; glycerol and urea, and the 50:50 mixture of the later are shown in Fig.2. Urea exhibits characteristic absorption bands in two main regions: $3700-3000 \mathrm{~cm}^{-1}$ (N-H amide stretching) and $1700-1300 \mathrm{~cm}^{-1}(\mathrm{~N}-\mathrm{H}$ amide bending and carbonyl group stretching), presenting three characteristic peaks located at 1675, 1618 and $1585 \mathrm{~cm}^{-1}$. Glycerol, on the contrary, has a broad band between 3700 - $3000 \mathrm{~cm}^{-1}(\mathrm{O}-\mathrm{H}$ stretching and bending) and the characteristic peaks of $\mathrm{C}-\mathrm{H}$ bonds in the region of $3000-$ 
$2800 \mathrm{~cm}^{-1}$ and $1500-1200 \mathrm{~cm}^{-1}$. Urea and glycerol mixture showed characteristics absorption bands of both pure components, though maximums shift towards higher wavenumbers were observed on the $3700-3000 \mathrm{~cm}^{-1}$ and $1700-1300 \mathrm{~cm}^{-1}$ regions, representative of H-bridges interactions between both compounds. Moreover, native cassava starch spectrum presents a wide band between $3700-3000 \mathrm{~cm}^{-1}$ corresponding to the O-H stretching and bending, another peak at $1643 \mathrm{~cm}^{-1}$ associated to the $\mathrm{O}-\mathrm{H}$ stretching in water molecules clusters with moderately strong H-bonded, and the characteristic bands of the $\mathrm{C}-\mathrm{O}-\mathrm{C}$ stretching vibrations and $\mathrm{C}-\mathrm{O}-\mathrm{H}$ bending vibrations in glycoside and pyranose rings in amylose and amylopectin at $1200-900 \mathrm{~cm}^{-1}[40,41]$.

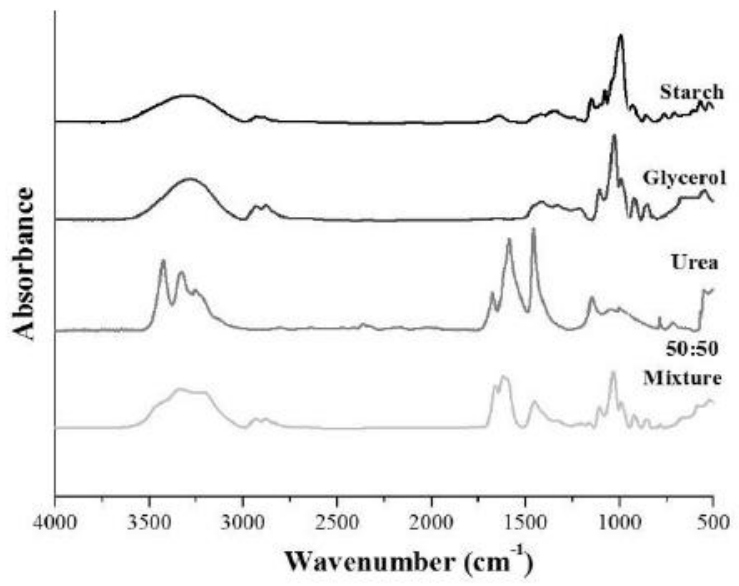

Fig.2: ATR-FTIR spectra of pure film components: starch, glycerol, urea and its 50:50 mixture.

Likewise, FTIR spectra of plasticised films with glycerol, urea and the mixture of both revealed the characteristic bands of the pure components. Nonetheless, variations in intensity and maximums shifts were observed indicating distinctive interactions among components. Main differences were displayed in $3700-3000 \mathrm{~cm}^{-1}, 3000-$ $2800 \mathrm{~cm}^{-1}, 1700-1500 \mathrm{~cm}^{-1}$ and $1200-900 \mathrm{~cm}^{-1}$ regions (Fig.3). Table 3 shows the most important absorption peaks in each spectral window.

On the one hand, $\mathrm{C}$ and $\mathrm{G}$ films revealed a broad and intense absorption band in $3700-3000 \mathrm{~cm}^{-1}$ region centred at $3281 \mathrm{~cm}^{-1}$, which is assigned to $\mathrm{O}-\mathrm{H}$ stretching and bending vibrations. Films containing urea on the other hand, presented three important contributions in this region: about 3200, 3345 and $3452 \mathrm{~cm}^{-1}$ (Fig.3a). The latter are attributed to the characteristic amide $\mathrm{N}-\mathrm{H}$ stretching peaks of urea (3254, 3327 and $3427 \mathrm{~cm}^{-1}$ ), although the significant shifts observed indicate -as expected- that these N-H groups are involved in the $\mathrm{H}-$ bridge interactions within the matrix. The individual contributions of each of these peaks to the band depend on the urea content,resulting relative areas of 3200 and $3345 \mathrm{~cm}^{-1}$ peaks the most affected (Table 3 ).

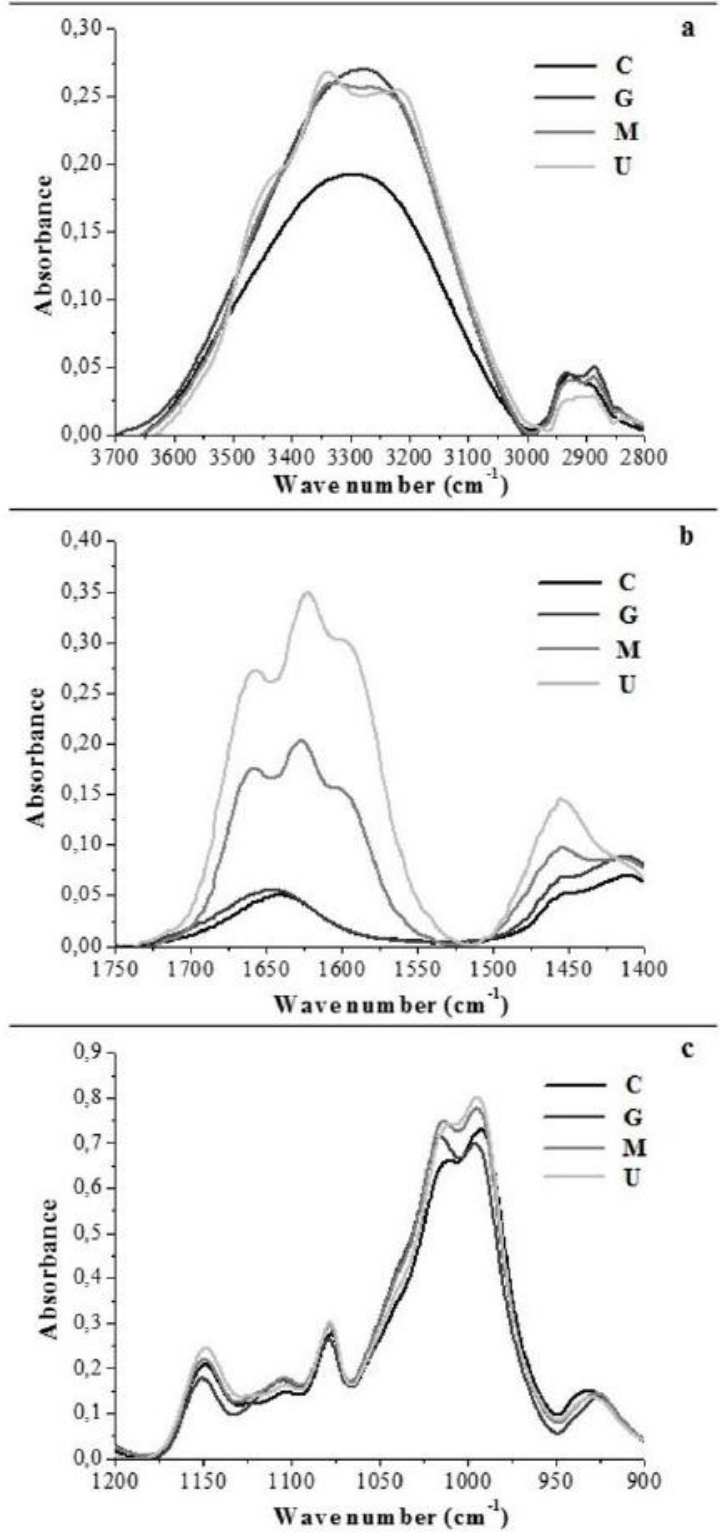

Fig.3: ATR-FTIR spectra of cassava starch-based films: unplasticized control $(C)$, plasticised with $25 \%$ glycerol $(G), 12.5 \%$ glycerol and $12.5 \%$ urea $(M)$ and $25 \%$ urea (U). Three main regions are shown: a) $3700-2800 \mathrm{~cm}^{-1}$; b) $1750-1400 \mathrm{~cm}^{-1}$; and c) $1200-900 \mathrm{~cm}^{-1}$.

In the spectral region between $3000-2800 \mathrm{~cm}^{-1}$ urea does not reveal any band, whereas glycerol has a band with two clear peaks at 2937 and $2875 \mathrm{~cm}^{-1}$. Cassava starch $\mathrm{C}$ and $\mathrm{G}$ films exhibit an analogous band though relative intensities shift due to the presence of glycerol's methylene groups (Table 3). Moreover, in films containing urea this band unfolds into three contributions with similar relative intensities (Table 3 ), indicating that the environment of $\mathrm{C}$ - 
Table 3. FTIR band deconvolution peaks in the analysed spectral windows of control cassava starch films $(C)$ and films plasticized with: glycerol $(G)$, urea $(U)$ and their mixture $(M)$.

\begin{tabular}{|c|c|c|c|c|}
\hline Film & $\mathrm{C}$ & $\mathrm{G}$ & $\mathrm{M}$ & $\mathrm{U}$ \\
\hline \multirow{3}{*}{$3700-3000 \mathrm{~cm}^{-1}$} & $3297.0(1)$ & $3281.9(1)$ & $3203.4(0.41)$ & $3199.6(0.48)$ \\
\hline & -- & -- & $3346.2(0.41)$ & $3343.2(0.34)$ \\
\hline & -- & -- & $3467.1(0.18)$ & $3458.8(0.18)$ \\
\hline \multirow{3}{*}{$3000-2800 \mathrm{~cm}^{-1}$} & $2886.0(0.36)$ & $2884.4(0.58)$ & $2881.3(0.43)$ & $2884.1(0.40)$ \\
\hline & -- & -- & $2914.6(0.26)$ & $2914.0(0.30)$ \\
\hline & $2931.1(0.64)$ & $2936.3(0.42)$ & $2938.1(0.31)$ & $2940.2(0.30)$ \\
\hline \multirow{3}{*}{$1700-1500 \mathrm{~cm}^{-1}$} & -- & -- & $1593.8(0.25)$ & $1587.6(0.32)$ \\
\hline & 1643.7 (1) & $1651.5(1)$ & $1628.5(0.45)$ & $1623.8(0.40)$ \\
\hline & -- & -- & $1664.8(0.30)$ & $1663.9(0.28)$ \\
\hline \multirow{8}{*}{$1200-900 \mathrm{~cm}^{-1}$} & $928.7(0.07)$ & $923.8(0.06)$ & $925.6(0.06)$ & $927.8(0.06)$ \\
\hline & $989.7(0.34)$ & $993.9(0.35)$ & $992.9(0.36)$ & $992.4(0.36)$ \\
\hline & $1016.9(0.23)$ & $1017.3(0.17)$ & $1016.5(0.19)$ & $1016.1(0.22)$ \\
\hline & $1045.9(0.12)$ & $1040.1 \quad(0.20)$ & $1041.2(0.17)$ & $1043.1(0.13)$ \\
\hline & $1078.8(0.06)$ & $1079.8(0.05)$ & $1079.3(0.05)$ & $1079.0(0.06)$ \\
\hline & $1101.8(0.06)$ & $1103.6(0.07)$ & $1102.9(0.06)$ & $1102.6(0.05)$ \\
\hline & $1124.6(0.03)$ & $1122.5(0.03)$ & $1123.4(0.03)$ & $1123.8(0.03)$ \\
\hline & $1152.0(0.09)$ & $1151.1(0.07)$ & $1150.3(0.08)$ & $1149.7(0.09)$ \\
\hline
\end{tabular}

In the case of deconvoluted bands each informed value corresponds to the peak position and in between brackets its relative contribution to the total band area.

$H$ groups' change in the presence of urea affecting its vibrational transition.

In the FTIR spectra, films containing urea present three similar signals in terms of peak position and relative contribution in the region comprised among $1700-1500$ $\mathrm{cm}^{-1}$ yet with higher absorbance in the $U$ samples (Table 3). The observed shifts with respect to pure urea peaks indicate that both plasticizer-matrix and plasticizer-water interactions occur in the material. Similar results were published by Wangy col. [26] in oxidized corn-starch films plasticised with urea, being the peak at $1659 \mathrm{~cm}^{-1}$ attributed to $\mathrm{C}=\mathrm{O}$ stretching (amide-I region) and the one at $1626 \mathrm{~cm}^{-1}$ assigned to N-H bending (amide-II region). In both $\mathrm{C}$ and $\mathrm{G}$ films, a single contribution could be seen in this region, associated with the $\mathrm{O}-\mathrm{H}$ bonds of the water molecules that interact with the matrix (Table 3). Shifts observed in $\mathrm{C}$ and $\mathrm{G}$ films compared to those of pure components (Fig.2 and 3b) proved to be less important than that seen in films containing urea ( $M$ and $U$ ). From these results, it is clear that urea-matrix interactions are stronger than glycerol-matrix ones. MayYu [17] have exhaustively analysed the effect of plasticizers containing amide groups on the properties of thermoplastic starch, revealing that the hydrogen bond-forming abilities with starch was higher for urea than for polyols. Thus, in films containing urea the reaming hydrophilic groups available for interaction with free water are reduced, leading to lower film water content as shown in Table 1.
An increase in urea content led to an increase in the intensity of the peak located at $1455 \mathrm{~cm}^{-1}$, which correlates with the $\mathrm{C}-\mathrm{N}$ bond stretching in urea structure. Wangy col. [26] associated the absorbance ratio of this peak to that of $2930 \mathrm{~cm}^{-1}\left(\mathrm{~A}_{1455} / \mathrm{A}_{2930}\right)$ to the superficial urea content of the material. The authors had observed a significant increase in $\mathrm{A}_{1455} / \mathrm{A}_{2930}$ ratio when its concentrations exceeded $30 \% \mathrm{w} / \mathrm{w}$ at the same time migration of this plasticizer to the surface of potato starch films had been detected by SEM. Despite the fact that $\mathrm{A}_{1455} / \mathrm{A}_{2930}$ doubled from $\mathrm{M}(3,5 \pm 0,6)$ samples to $\mathrm{U}(8 \pm$ $0,6)$, urea superficial crystallisation was not observed in either samples probably because urea contents assayed were below those reported by Wangy col. [26] for urea migration to occur. Nonetheless, such differences can only be attributed to the greater concentration of urea molecules, and therefore $\mathrm{C}-\mathrm{N}$ bonds, in films with $25 \%$ of urea.

As shown in Fig.3c, in the fingerprint region of the spectrum all films components absorb, presenting distinctive peaks and intensities. Since in this region the major contributions are related to the starch matrix no major spectral variations were observed. Besides, the bands in this region of the infrared spectrum result mainly from $\mathrm{C}-\mathrm{O}$ and $\mathrm{C}-\mathrm{C}$ vibrational modes that are highly coupled, therefore the assignment of individual bands results difficult [42]. The main contributions found are shown in Table 3. 
Table 4. Glass transition temperature, thickness and tensile resistance properties of control cassava starch films $(C)$ and films plasticized with: glycerol $(G)$, urea $(U)$ and their mixture $(M)$.

\begin{tabular}{lllllll}
\hline Film & Tg $\left({ }^{\circ} \mathrm{C}\right)$ & $\begin{array}{l}\text { Thickness } \\
(\mu \mathrm{m})\end{array}$ & $\begin{array}{l}\mathrm{R}_{\max } \\
(\mathrm{MPa})\end{array}$ & $\begin{array}{l}\mathrm{E}_{\max } \\
(\%)\end{array}$ & $\begin{array}{l}\mathrm{Ec} \\
(\mathrm{MPa})\end{array}$ & $\begin{array}{l}\mathrm{Eg} \\
\left(\mathrm{kJ} / \mathrm{m}^{3}\right)\end{array}$ \\
\hline $\mathrm{C}$ & $68.3 \pm 1.8^{\mathrm{c}}$ & $75.8 \pm 2.4^{\mathrm{a}}$ & $61.8 \pm 2.9^{\mathrm{b}}$ & $6.1 \pm 0.8^{\mathrm{a}}$ & $1936 \pm 376^{\mathrm{b}}$ & $1995^{\mathrm{a}} \pm 344^{\mathrm{c}}$ \\
$\mathrm{G}$ & $37.8 \pm 0.5^{\mathrm{b}}$ & $75.9 \pm 5.3^{\mathrm{a}}$ & $2.2 \pm 0.6^{\mathrm{a}}$ & $47.3 \pm 9.6^{\mathrm{b}}$ & $14 \pm 3^{\mathrm{a}}$ & $1091 \pm 73^{\mathrm{a}}$ \\
$\mathrm{M}$ & $35.0 \pm 1.2^{\mathrm{b}}$ & $74.5 \pm 5.8^{\mathrm{a}}$ & $2.9 \pm 0.3^{\mathrm{a}}$ & $68.9 \pm 4.5^{\mathrm{b}}$ & $7 \pm 2^{\mathrm{a}}$ & $977^{\mathrm{a}} \pm 122^{\mathrm{a}}$ \\
$\mathrm{U}$ & $13.6 \pm 1.0^{\mathrm{a}}$ & $74.9 \pm 3.1^{\mathrm{a}}$ & $3.0 \pm 0.4^{\mathrm{a}}$ & $81.8 \pm 7.2^{\mathrm{c}}$ & $29 \pm 7^{\mathrm{a}}$ & $1740 \pm 99^{\mathrm{b}}$ \\
\hline
\end{tabular}

Reported values corres pond to the mean \pm standard deviation.

The peaks between 990 and $1030 \mathrm{~cm}^{-1}$ were attributed to the anhydroglucose ring $\mathrm{C}-\mathrm{C}, \mathrm{C}-\mathrm{O}, \mathrm{C}-$

$\mathrm{H}$ bonds stretching and $\mathrm{C}-\mathrm{O}-\mathrm{H}$ bending modes [25, 43], while those at around 1150 and $1080 \mathrm{~cm}^{-1}$ were assigned to $\mathrm{C}-\mathrm{O}-\mathrm{H}$ stretching in starch [44]. The slight deviations detected in peaks maximums were attributed to plasticizers-starch interaction.

In addition, many authors have emphasised that both the absorbance ratios of the peaks at 994 and $1047 \mathrm{~cm}^{-1}$ relative to that of $1022 \mathrm{~cm}^{-1}$ could be indicative of the degree of crystallinity of starch [42, 43]. In line with these studies, C films presented A990/A 1022 and $\mathrm{A}_{1047} / \mathrm{A}_{1022}$ ratios $15 \%$ lower than native starch, since in $C$ films starch had been gelatinised and therefore present a rather amorphous gel structure [45]. Likewise, films plasticised with $U$ showed similar results than $\mathrm{C}$ films. Films containing glycerol in their formulation ( $\mathrm{M}$ and $\mathrm{G}$ ) presented significantly higher $\mathrm{A}_{990} / \mathrm{A}_{1022}$ and $\mathrm{A}_{1047} / \mathrm{A}_{1022}$ ratios $(\mathrm{p}<0.05)$, that should be indicative of more crystalline regions in the films structure. Nonetheless, these unusual results could be attributed to the band at $995 \mathrm{~cm}^{-1}$ that correspond to the vibration of the skeleton $\mathrm{C}-\mathrm{C}$ and the peak at $1045 \mathrm{~cm}^{-1}$ as sociated to the stretching of the $\mathrm{C}-\mathrm{O}$ linkage in $\mathrm{Cl}$ and $\mathrm{C} 3$ in glycerol [46]. Consequently, this criterion would not be adequate to estimate the crystallinity of plasticised starch films.

\section{I.3.2. Differential Scanning Calorimetry (DSC)}

The DSC measurements served to determine the relaxation transitions of starch films (Table 4). The registered glass transition temperature $(\mathrm{Tg})$ value for $\mathrm{C}$ films proved to be noticeably higher than that reported for films including plasticizer. Such results are in agreement with transition temperature registered for unplasticized starch films by other authors in literature [47, 48]. Moreover, a significant decrease $(\mathrm{p}<0.05)$ in the $\mathrm{Tg}$ of cassava starch films was observed in films plasticised with urea $(\mathrm{U})$, being this effect less important in the coplasticisation with glycerol (M). Lowering of $\mathrm{Tg}$ is regarded as an indicative of plasticisation efficiency [6], therefore these results imply that urea is a more efficient a plasticizer than glycerol and their mixture.

I.3.3. Mechanical testing and SEM

characterisation
Furthermore, the mechanical behaviour of starch-based films depends heavily on their composition and thickness, yet all studied films had an average thickness circa $75 \mu \mathrm{m}$ with no significant differences ( $p>0.05)$ among samples (Table 4).

Mechanical tensile resistance parameters of cassava starch-based films are shown in Table 4. From the results, it is clear that unplasticized films (C) present a brittle behaviour due to the strong cohesive forces among amylose and amylopectin chains [6]. The addition of 25 $\%$ w/w of plasticizer had a substantial impact on films maximum resistance $\left(R_{\max }\right)$ and elongation $\left(E_{\max }\right)$ as well as their elastic modulus $(\mathrm{Ec})$, regardless of their nature (Table 4). Plasticised films mechanical profiles are shown in Fig.4.

As expected, the films mechanical behaviour was markedly affected by the type of plasticizer. Films plasticised with urea (U) resulted more flexible and resistant than that plasticised with the same content of glycerol (G). A significant increase $(\mathrm{p}<0.05)$ was observed in the elongation at break and tenacity of the material, although no significant differences were observed in the maximum tensile strength at rupture (Table 4). The materials elastic modulus follow a similar tendency (Table 4), thus it could be concluded that in terms of mechanical performance urea is a more efficient plasticizer than glycerol, most probably due to molecular size difference between both plasticizers [6]. In this regard, the higher mechanical resistance of $U$ films is attributed to the stronger interactions between urea and the starch matrix, which was evidenced by FTIR analysis. With regards to film flexibility, Ivaničy col. [33] had revealed an opposite behaviour studying native corn starch films plasticised with urea and glycerol, reporting higher $\mathrm{Tg}$ values for urea plasticised starch films; therefore, in their study films were in a vitreousamorphous state at ambient temperature which would explain their brittleness. Differences are attributed to processing conditions since in this work plasticizer was incorporated before starch gelatinis ation.

When both plasticizers were added to the matrix, the resultant mechanical profile is in between that of a flexible and a flexible-tenacious material, exhibiting 
though poorer characteristics than that of films with a single plasticizer. In spite the fact that there are no significant differences $(p>0.05)$ in matrix elongation at break between $U$ and $M$ samples, both the maximum strength and the tenacity of the latter are significantly lower $(\mathrm{p}<0.05)$ than those of films plasticised either with urea or glycerol (U and $\mathrm{G}$, respectively). Presumably, Hbridges interactions could be favoured among urea and glycerol molecules rather than interactions with the polymer matrix, negatively affecting the films mechanical properties.
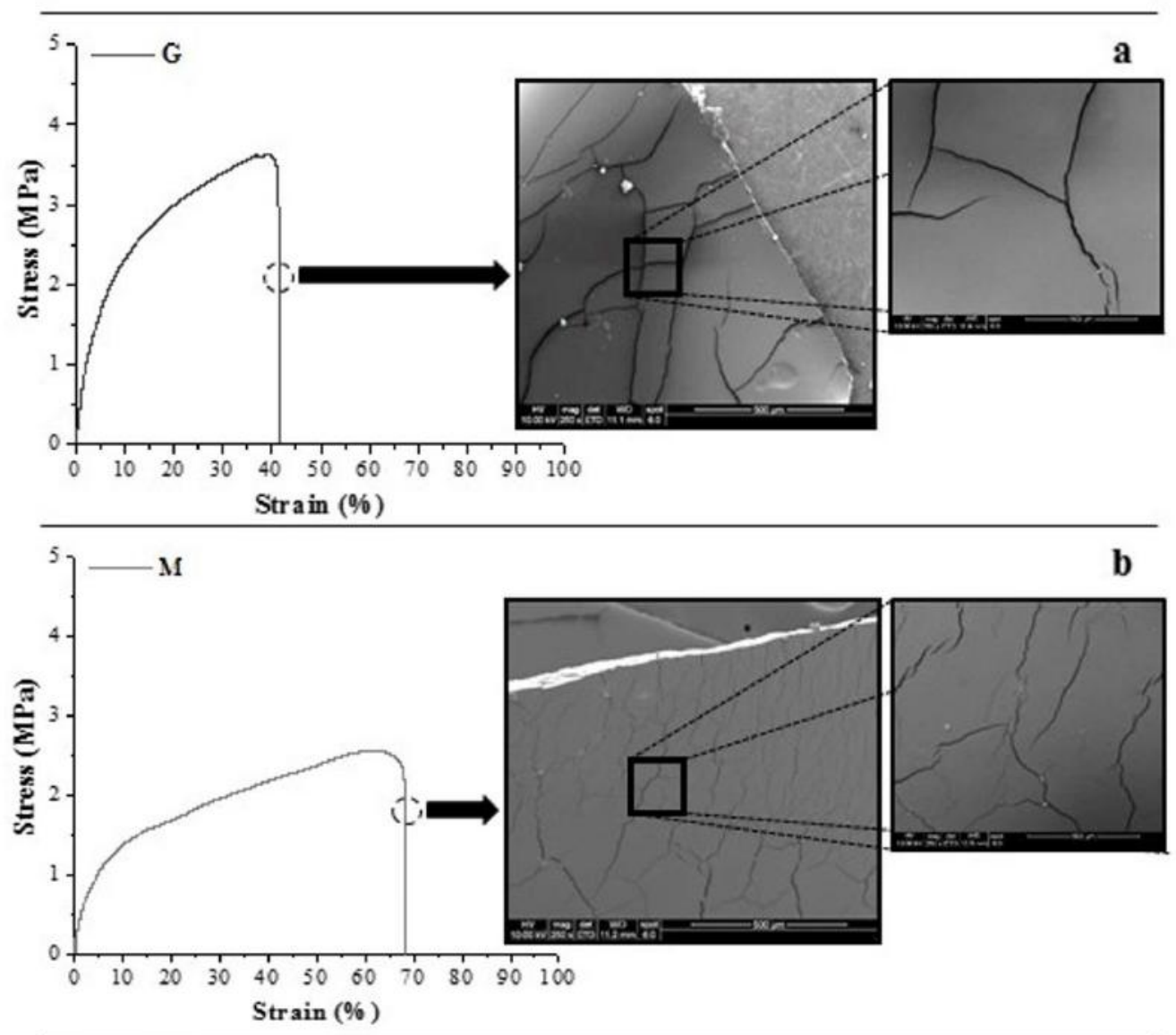

b

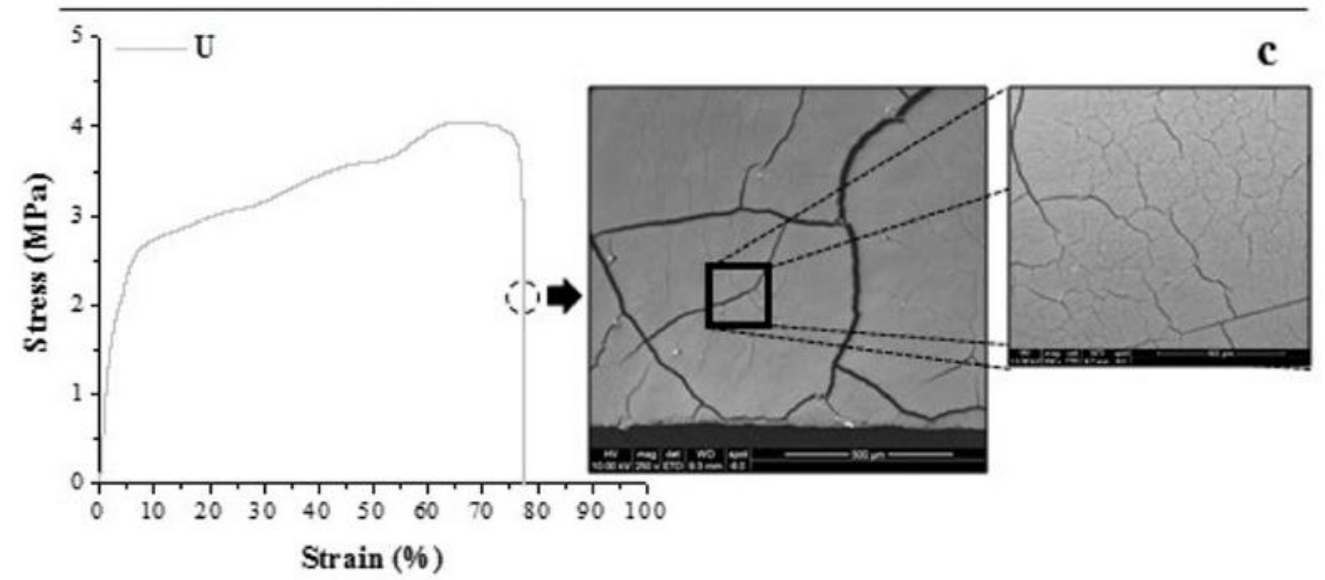

Fig.4: Tensile stress-strain curves and SEM micrograph offractured plasticised cassava starch films with: a) $25 \%$ glycerol $(G)$; b) $12.5 \%$ glycerol and $12.5 \%$ urea (M); and c) $25 \%$ urea (U). The SEM micrographs correspond to the cross section and a close-up image of the films surface.

Moreover, the topography of the surface and cross sections of the plasticised films subjected to tensile rupture test were studied using the SEM technique. Fig.4 shows the films probe rupture cross section and surface close-up of cassava starch films containing different types of plasticizer. Cracks or micro-cracks were observed on the surface of the materials in the direction in which the fracture of the specimen was propagated. However, films 
with the addition of urea presented smaller cracks in every other direction probably because of the amorphous structure of the plasticised matrix. Besides, it should be remarked that no superficial urea migration, nor crystallisation, was detected. The micro-cracks observed result from the non-elastic elongations of films containing urea (detail box in Fig.4b and 4c). These results proved again the more flexible and resistant structure developed in U films, due to urea-starch interactions development as was confirmed by FTIR.

I.4. Principal Components Analysis (PCA) In order to illustrate the aforementioned effects of the plasticizers on the polymer matrixes a PCA was carried out (Fig.5). Two separate analysis were done: one comparing plasticised and unplasticized samples all together (Fig.5a), and another one comparing only plasticised films to evaluate the effect of plasticizer type (Fig.5b). Both analyses gave a cophenetic correlation coefficient value circa 1 , showing that such data grouping is representative of the experimental variables studied. In the first case, it is clear that the first main component (CP1) -that explains the $70.2 \%$ of the total variancerepresents the plasticisation effect on starch films. In comparis on, considering the plasticised films (left side of Fig.5a) it can be seen that $U$ films generate more important changes in films properties, since it is further away from the centre axis. Considering that $\mathrm{C}$ and $\mathrm{M}$ samples were not considerably affected by the second main component $(\mathrm{CP} 2)$, in this case representing the $25.7 \%$ of the total variance, it was therefore attributed to the presence of urea or glycerol as single plasticizers.

Similarly, in the second case (Fig.5b) this analysis showed that: the first main component (CP1) that explains $76.1 \%$ of the total variance, associated with the presence of glycerol in the film matrix; whereas the other main component (CP2) attributed to single or co-plasticisation, accounts for the remaining $23.9 \%$. The latter effect correlates with that seen in the first case, indicating that overall co-plasticisation with 50:50 urea and glycerol mixtures have a lower impact on films end properties than single compound plasticisation.

This analysis summarizes the previously detailed results, indicating a stronger influence and efficiency of urea as plasticizer of the starch matrix.
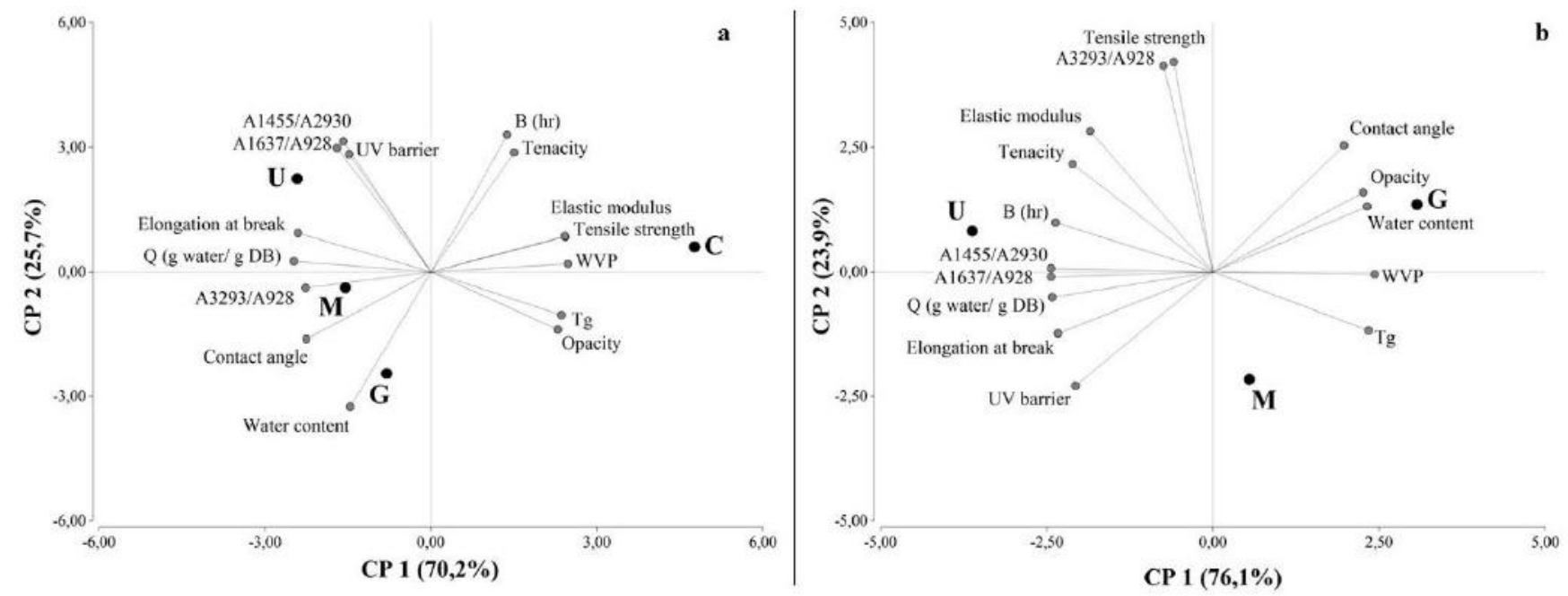

Fig.5. Principal components analysis (PCA) considering films properties with significant differences for cassava starch films, comparison of: a) plasticised ( $G, M$ and $U$ ) and unplasticized (C) films, and b) films plasticized with $25 \%$ w/w of glycerol $(G)$, urea $(U)$ and their 50:50 mixture $(M)$.

\section{CONCLUSION}

In conclusion, urea, glycerol and their mixture were compatible plasticizers for cassava starch-based matrices, not detecting surface migration within the plasticizer's content tested $(25 \% \mathrm{w} / \mathrm{w})$. Even though all samples contained the same amount of plasticizer, the addition of urea resulted in lower film moisture content. Films containing urea showed enhanced optical properties, especially the UV barrier capacity, since this plasticizer exhibited an electronic transition in this spectral region; though films containing a mixture of both plasticizers presented the highest UV-Vis absorption (200 - $700 \mathrm{~nm}$ ).

Plasticizer-polymer interactions as well as those involving water molecules were evidenced by peak shifts observed in ATR-FTIR spectra: in particular, the detected shift to lower frequencies at 3300-3000 and 1700-1300 $\mathrm{cm}-1$ regions, suggested stronger $\mathrm{H}$-bonding interaction between starch $\mathrm{O}-\mathrm{H}$ groups and $\mathrm{N}-\mathrm{H}$ and $\mathrm{C}=\mathrm{O}$ groups in urea than those between $\mathrm{O}-\mathrm{H}$ pairs. In addition, the higher plasticizing efficiency of urea was demonstrated by both 
the decrease in $\mathrm{Tg}$ values and the mechanical properties enhancement. On the contrary, the co-plasticization of the starch films with glycerol and urea 50:50 mixture resulted in lower mechanical resistance. As discussed, this behaviour could be ascribed to H-bridges interactions among urea and glycerol molecules -which were evidenced by FTIR of the mixture- reducing the plasticizers' interactions with the polymer matrix. Hence, the latter's use for starch- based films plasticization should be discouraged.

The obtained results provide a starting point for the study of applications of starch-based biomaterials as active compounds for controlled-release systems, particularly for agronomic purposes considering that urea is a commonly used fertilizer. In this regard, further research on co-plasticization with urea should be encouraged.

\section{ACKNOWLEDGEMENTS}

This work was supported by the Agencia Nacional de Promoción Científica y Tecnológica (ANPCyT, Project PICT 2011-1213 and 2015-0921) and the Consejo Nacional de Investigaciones Científicas y Técnicas (CONICET). Florencia Versino wishes to thank CONCIET as well for a Doctoral Fellowship. Authors would also like to thank Ms. Marina Urriza for her technical as sistance.

\section{REFERENCES}

[1] L. Chen, et al. (2008). Carbohydrate Polymers. 72(2): p. 342-348.

[2] P. Rychter, et al. (2016). Carbohydrate Polymers. 137(1): p. 127-138.

[3] H. Horinouchi, et al. (2008). Crop Protection. 27(3): p. 859-864.

[4] A.P. Bilck, M.V.E. Grossmann, and F. Yamashita (2010). Polymer Testing. 29(4): p. 471-476.

[5] M.M. Moreno and A. Moreno (2008). Scientia Horticulturae. 116(3): p. 256-263.

[6] R. Sothornvit and J.M. Krochta (2005). Plasticizers in edible films and coatings, in Innovations in Food Packaging, J.H. Han, Editor. Academic Press: London. p. 403-433.

[7] M.G.A. Vieira, et al. (2011). European Polymer Journal. 47(3): p. 254-263.

[8] S. Rivero, et al. (2016). Food Biophysics. 11(2): p. 117-127.

[9] M.C. Galdeano, et al. (2009). Materials Science and Engineering C. 29(2): p. 532-538.

[10] S. Mali, et al. (2005). Carbohydrate Polymers. 60(3): p. 283-289.

[11] A.P. Mathew and A. Dufresne (2002). Biomacromolecules. 3(5): p. 1101-1108.
[12] Y. Zhang and J.H. Han (2006). Journal of Food Science. 71(2): p. 109-118.

[13] M.A. García, M.N. Martino, and N.E. Zaritzky (2000). Starch - Stärke. 52(4): p. 118-124.

[14] P.V.A. Bergo, et al. (2008). Packaging Technology and Science. 21(2): p. 85-89.

[15] A.N. Ghebremeskel, C. Vemavarapu, and M. Lodaya (2007). International Journal of Pharmaceutics. 328(2): p. 119-29.

[16] H. Liu, et al. (2011). Journal of Polymer Science Part B: Polymer Physics. 49(14): p. 1041-1049.

[17] X. Ma and J. Yu (2004). Starch - Stärke. 56(11): p. 545-551.

[18] M. Rodríguez, et al. (2006). Food Research International. 39(8): p. 840-846.

[19] T.M. Stein, S.H. Gordon, and R.V. Greene (1999). Carbohydrate Polymers. 39(1): p. 7-16.

[20] R.A. Talja, et al. (2007). Carbohydrate Polymers. 67(3): p. 288-295.

[21] O.V. López, et al. (2013). Materials Science and Engineering C. 33(3): p. 1583-91.

[22] E.M.A.R. Fialho, et al. (2017). Materials Science and Engineering C. 78: p. 932-941.

[23] F.G. Torres, et al. (2011). Materials Science and Engineering C. 31(8): p. 1737-1740.

[24] X.F. Ma, J.G. Yu, and Y.B. Ma (2005). Carbohydrate Polymers. 60(1): p. 111-116.

[25] X.F. Ma, J.G. Yu, and J.J. Wan (2006). Carbohydrate Polymers. 64(2): p. 267-273.

[26] J.L. Wang, F. Cheng, and P.X. Zhu (2014). Carbohydrate Polymers. 101(1): p. 1109-15.

[27] S. Wang, et al. (2015). Carbohydrate Polymers. 117: p. 133-139.

[28] X. Jiang, et al. (2012). Journal of Applied Polymer Science. 125(1): p. 697-703.

[29] X. Mo and X. Sun (2001). Journal of the American Oil Chemists' Society. 78(8): p. 867-872.

[30] O.V. López, M.A. García, and N.E. Zaritzky (2008). Carbohydrate Polymers. 73(4): p. 573-581.

[31] R. Sothornvit, D.S. Reid, and J.M. Krochta (2002). Transactions of the ASAE. 45(5): p. 1479-1484.

[32] F. Versino and M.A. García (2014). Industrial Crops and Products. 58(1): p. 305-314.

[33] F. Ivanič, et al. (2017). European Polymer Journal.

[34] B.E. Elizalde, A.M.R. Pilosof, and G.B. Bartholomai (1996). Journal of Food Science. 61(2): p. 407-409.

[35] L. Castillo, et al. (2013). Carbohydrate Polymers. 95(2): p. 664-674.

[36] J.A. Di Rienzo, et al. (2011).

[37] W.A. Zisman (1964). Relation of the Equilibrium Contact Angle to Liquid and Solid Constitution, in Contact Angle, Wettability, and Adhesion, F.M. 
Fowkes, Editor. American Chemical Society:

Washington DC. p. 1-51.

[38] C.T. Andrade, et al. (2005). Carbohydrate Polymers. 61(4): p. 407-413.

[39] M.A. Bertuzzi, et al. (2007). Journal of Food Engineering. 80(3): p. 972-978.

[40] X. Ma, et al. (2007). Macromolecular Materials and Engineering. 292(4): p. 503-510.

[41] J. Piermaria, et al. (2011). Food Hydrocolloids. 25: p. 1261-1269.

[42] P. Rubens, et al. (1999). Carbohydrate Polymers. 39(3): p. 231-235.

[43] I. Capron, et al. (2007). Carbohydrate Polymers. 68(2): p. 249-259.

[44] W. Shujun, Y. Jiugao, and Y. Jinglin (2005). Polymer Degradation and Stability. 87(3): p. 395401.

[45] P. Myllärinen, et al. (2002). Carbohydrate Polymers. 48(1): p. 41-48.

[46] E. Basiak, A. Lenart, and F. Debeaufort (2018). Polymers. 10(4): p. 412.

[47] Y.P. Chang, P.B. Cheah, and C.C. Seow (2000). JFS: Food Engineering and Physical Properties. 65(3): p. 445-451.

[48] J. Perdomo, et al. (2009). Carbohydrate Polymers. 76(2): p. 305-313. 